\title{
O ACESSO À JUSTIÇA NA PERCEPÇÃO DAS CORTES EUROPEIA E INTERAMERICANA DE DIREITOS HUMANOS E DO TRIBUNAL DE JUSTIÇA DA UNIÃO EUROPEIA
}

\author{
Bruno Makowiecky Salles ${ }^{1}$ \\ Paulo Márcio Cruz ${ }^{2}$
}

\section{RESUMO}

O presente artigo objetiva estudar o Acesso à Justiça, positivado em relevantes documentos internacionais, à luz da percepção das Cortes Europeia e Interamericana de Direitos Humanos, assim como do Tribunal de Justiça da União Europeia e das contribuições doutrinárias correlatas. Ao final, o conteúdo pesquisado é utilizado para a formulação de um conceito jurídico de Acesso à Justiça sob a ótica dos sistemas internacionais.

PALAVRAS-CHAVE: Acesso à Justiça; Sistemas Internacionais; Conceito.

Recebido em: 11 de maio. 2021

Aceito em: 12 de agosto. 2021

\footnotetext{
1 Doutor em Ciência Jurídica pelo Programa de Pós-Graduação Stricto Sensu em Ciência Jurídica PPCJ/UNIVALI, Dottore di Ricerca in Scienze Giuridiche pela Universitá di Perugia - Itália, Juiz de Direito do Tribunal de Justiça de Santa Catarina.

${ }^{2}$ Doutor em Direito do Estado pela Universidade Federal de Santa Catarina. Professor e permanente e coordenador do Programa de Pós-Graduação Stricto Sensu em Ciência Jurídica - PPCJ/UNIVALI. Professor visitante das Universidade de Perugia (Itália) e Alicante (Espanha).
} 


\title{
THE ACCESS TO JUSTICE FROM PERCEPTION OF EUROPEAN AND THE INTER-AMERICAN COURTS OF HUMAN RIGHTS AND THE COURT OF JUSTICE OF THE EUROPEAN UNION
}

\begin{abstract}
This article aims to study Access to Justice, stablished in important international documents, in the light of doctrinal contributions and the perception of the European and Inter-American Courts of Human Rights and the Court of the European Union. In the end, the content studied is considered for the formulation of a legal concept of Access to Justice in the view of international systems.
\end{abstract}

KEYWORDS: Access to Justice; International Systems; Concept.

\section{INTRODUÇÃO}

Diante da multiplicidade de sentidos da expressão Acesso à Justiça (lato sensu) e da riqueza dos vários aspectos envolvidos na matéria, já se observou que "Il est paradoxalement plus aisé de définir ce que n'est pas le droit d'áccès au juge plutôt que d'essayer de formaliser ce qui'il est” (DONIER et al, 2003, p. 32-33) 3. Vê-se que Acesso à Justiça é uma daquelas expressões caleidoscópicas, refletindo um conceito que "draws the mind to a multitude of questions about the sources of injustice and the legal systems around the world that have developed to help provide an avenue for redressing a wrong" (RICE; REISMAN, 2009, p. $257)^{4}$. Enquanto alguns adotam visões mais estreitas, outros incluem na noção de Acesso à Justiça quase todos os problemas dos sistemas jurídicos (JOHNSON JR, 1978-1979, p. 07-08), fazendo com que delimitações sejam necessárias para uma melhor compreensão.

Atualmente, o Acesso à Justiça é considerand o um elemento integrante da categoria dos Direitos Humanos (CÂMARA, 2002, p. 03), acha-se previsto nas Constituições de diversos países como Direito Fundamental (CICHOCKI NETO, 2009, p. 87-95) e pode ser considerado, mesmo nos ordenamentos nos quais não existe expressa previsão normativa, um direito implícito no Estado de Direito, no regime democrático e na separação dos Poderes (PONTES DE MIRANDA, 1987, p. 104), mostrando-se também inerente, sobretudo nos sistemas ligados

\footnotetext{
3 Tradução livre: "É paradoxalmente mais fácil definir o que não é o direito de acesso ao juiz do que tentar forma lizaro que ele é".

4 Tradução livre: "chama a mente para uma infinida de de questões sobre as formas de injustiça e os sistemas jurídicos, desenvolvidos a o redor do mundo, para construir caminhos destinados a corrigir um erro".
}

Rev. CEJUR/TJSC |Florianópolis (SC)| v.9. n.1|e364| p.01-19 |Janeiro-Dezembro | 2021. 
à família jurídica da Common Law, à cláusula do due process of law. A ideia de fundo é a de reconhecer a prerrogativa de cada indivíduo de avançar pretensões e que suas reivindicações e seus direitos sejam reconhecidos em iguald ade de condições (CONFORD, 2016, p. 29), seja na via judicial ou em espaços extrajudiciais.

Este $\operatorname{artigo~}^{5}$ propõe-se a estudar o Acesso à Justiça (lato sensu), positivado em relevantes documentos internacionais, à luz de contribuições doutrinárias e da percepção das Cortes Europeia e Interamericana de Direitos Humanos, assim como do Tribunal de Justiça da União Europeia. Ao final, o conteúd o pesquisado é utilizado para a formulação de um conceito jurídico de Acesso à Justiça sob a ótica dos sistemas internacionais.

Em relação à metodologia, cabe o registro de que, na fase de investigação, foi empregado o métod o indutivo. $\mathrm{O}$ texto restou composto sob a base lógica indutiva. As diversas fases da pesquisa foram auxiliadas com recurso às técnicas do referente, categoria, conceito operacional e pesquisa bibliográfica (PASOLD, 2015).

\section{ACESSO À JUSTIÇA (LATO SENSU) EM SISTEMAS INTERNACIONAIS.}

\subsection{Previsões em documentos internacionais.}

Os documentos internacionais caracterizam-se por estipularem os direitos essenciais do ser humano e por serem protegidos por garantias institucionalizadas, instando os Estados-Nação a atender as normas internacionais e respeitar a ordem supranacional, sob pena de responsabilização (RAMOS, 2013, p. 27 e 31). O presente artigo gravita em torno desta ideia geral, sem a intenção de aprofundar na descrição particularizada dos sistemas universal e regionais de Direitos Humanos ${ }^{6}$, nas coordenações entre eles, na exposição de suas funções também consultivas e não-contenciosas, ou, ainda, na investigação das atribuições dos Tribunais Penais Internacionais na tutela da paz. Também não cabem distinções teóricas aprofundadas acerca dos planos dos Direitos Humanos e do Direito Comunitário, com suas complexas inter-relações (RUSSOWSKY, 2012, p. 01-21), não se tendo a pretensão de aprofundar ou exaurir os atos normativos conectados ao último, como Tratados Comunitários

\footnotetext{
${ }^{5} \mathrm{O}$ texto contém fragmentos da seguinte obra: SALLES, 2021, p. 71-89.

6 A título de informação, cabe referir que o sistema internacional tem como parâmetro a a valiação da administração da justiça no Estado em que a reclamação individual é ajuizada, apenas admitindo a responsabilização internacional de tal Estado caso se configure o fracasso dos remédios internos postos à disposição do lesado. Por outro lado, os sistemas regionais baseiam-se em Convenções firmadas pelos Estados que tendem a permitir um controle mais direto dos direitos, normalmente prevendo mecanismos próprios de supervisão e tutela. A propósito: MENDONÇA, 2016.p. 362.
} Rev. CEJUR/TJSC |Florianópolis (SC)| v.9. n.1|e364| p.01-19 |Janeiro-Dezembro |2021. 
ou Diretivas ${ }^{7}$. A intenção, em resumo, é descrever os os standards internacionais sobre o tema, importantes em razão da realidade paralela presente entre ordenamentos nacionais e internacionais e da "funzione unificante" que estes últimos exercem na criação de "un sostrato comune di valori condivisi tra i diversi Paesi", inclusive no que se refere ao Acesso à Justiça (OSTI, 2016, p. 04) ${ }^{8}$.

Posto isso, tem-se que, dentro do chamado sistema universal ou global de direitos humanos, a Organização das Nações Unidas (ONU) editou, em 10 de dezembro de 1948, a Declaração Universal dos Direitos do Homem (DUDH). Apesar das controvérsias em torno de sua natureza de recomendação internacional, como tal não-vinculante (soft law), trata-se de um documento material e consuetudinariamente respeitado pelos Estados, além de ter a juridicidade reforçada por Pactos subsequentes (CRUZ; SALLES, 2018, p. 25-36). A proteção judicial dos direitos humanos, no sistema global, é exercida pela Corte Internacional de Justiça (CIJ), órgão das Organização das Nações Unidas sediado em Haia, na Holanda, cuja atuação é subsidiária, isto é, exercida após o esgotamento das jurisdições nacionais, e oponível aos Estados que tenham aderido à sua Jurisdição (RAMOS, 2013, p. 95).

Para a Corte de Haia, certos direitos humanos compõem os princípios gerais do Direito Internacional, vinculando até os Estados não-contratantes dos pactos que os preveem ${ }^{9}$. E, no campo do Acesso à Justiça, a Declaração Universal dispõe que todo ser humano tem direito a "receber dos tribunais nacionais competentes remédio efetivo para os atos que violem os direitos fundamentais que lhe sejam reconhecidos pela constituição ou pela lei"10 (DUDH, art. $8^{\circ}$ ). Nesse sentido, a norma enuncia quatro elementos do direito Acesso à Justiça: estar disponível a qualquer um, independentemente da nacionalidade, traduzir-se em um remédio efetivo contra a violação, fazer-se presente em todos os Países e ser usufruível em todos os casos de violações de direitos do interessado (LENZERINI; MORI, 2009, p. 150-151).

\footnotetext{
7 Para maiores informações, são relevantes em tema de Acesso à Justiça as Diretivas n. 2005/85/EC, 2003/8/EC, 2013/32/EUe 2008/52/EC. A respeito: OSTI, 2016,p. 129-130.

8 Tradução livre: "função unifica dora" e "um substra to comum de va lores compartilha dos entre os diversos países".

9 No ponto, a doutrina registra que "os direitos humanos compõem os princípios gerais do Direito Internacional, uma vez que a mesma Corte Internacional de Justiça reconheceu, no Parecer Consultivo relativo à Convenção de Prevenção e Repressão a Crime de Genocídio, que os princípios protetores dos direitos humanos daquela Convenção devem ser considerados princípios gerais de Direito Internacionale vintulam mesmo Esta dos não contra tantes". RAMOS, 2013, p. 30.

${ }^{10} \mathrm{O}$ mesmo documento, em caráter complementar a o art. $8^{\circ}$, a inda assegura, no art. 10 , que qua lquer pessoa tem o direito a que sua causa seja aprecia da de forma equitativa por um Tribunal independente e imparcial, que decida sobre seus direitos e obrigações e sobre acusações em matéria criminal.
} 
Sobre o tema, a doutrina ensina que:

Emancipado no âmbito internacional como norma fundamental dotada de eficácia irradiante, cuja observância é irrenunciável em todas as relações públicas e privadas, no âmbito da Organização das Nações Unidas serviu para justificar, ao lado da consagração do princípio do primado do direito, a instituição do Tribunal Internacional de Justiça como mecanismo de viabilização do acesso dos Estados à jurisdição internacional, sempre que figurada hipótese de descumprimento dos preceitos da Carta, das decisões normativas dos seus Órgãos ou de outras normas de direito internacional. A DUDH, de 1948, revelada como conjunto de princípios representativos de um ideal comum a ser alcançado por todos os povos e nações, dotado de projeção universal e passível de ser invocado, em tese, por qualquer pessoa contra qualquer Estado, incorporou, no seu artigo 10, o enunciado do acesso ao direito e à justiça como valor indispensável à convivência humana, cuja violação autoriza a responsabilização internacional dos Estados (MENDONÇA, 2016,p. 76).

Para efeitos do sistema regional europeu, releva consignar que, como fruto dos trabalhos do Conselho da Europa, foi firmada em Roma, em 04 de novembro de 1950, entrando em vigor a partir do ano de 1953, a Convenção Europeia de Direitos Humanos (CEDH). A norma convencional, cuja natureza é vinculante aos Estados que a ratificaram e que hoje já foi aditada por inúmeros protocolos adicionais, garante que "Qualquer pessoa tem direito a que a sua causa seja examinada, equitativa e publicamente", em julgamento, como regra, público e proferido em prazo razoável, por um tribunal independente e imparcial, estabelecido "pela lei, o qual decidirá, quer sobre a determinação dos seus direitos e obrigações de carácter civil, quer sobre o fundamento de qualquer acusação em matéria penal dirigida contra ela" (CEDH, art. $6^{\circ}$ ). A mesma Convenção ainda consagra o Acesso, a todos quantos tiverem malferidos os direitos e liberdades nela reconhecidos, a um recurso efetivo perante instâncias nacionais (CEDH, art. 13). A proteção deste e de outros direitos humanos na esfera regional europeia é exercida pela Corte Europeia Direitos Humanos (Corte EDH), situada em Estrasburgo, na França, a quem compete resolver lides sobre a aplicação e a interpretação da Convenção, e cujas decisões obrigam e responsabilizam os Estados que tenham reconhecido a sua Jurisdição (RAMOS, 2013, p. 159).

No sistema do continente americano, a Convenção Americana de Direitos Humanos (CADH), criada no bojo da Organização dos Estados Americanos (OEA) e conhecida como Pacto de San José da Costa Rica, de 1969 e vigorante em 1978, assegura que "Toda pessoa tem direito a ser ouvida, com as devidas garantias e dentro de um prazo razoável, por um juiz ou tribunal competente, independente e imparcial", estabelecido ex ante e com atribuições nas esferas civil, penal, trabalhista, fiscal ou de qualquer outra natureza $\left(\mathrm{CADH}\right.$, art. $\left.8^{\circ}\right) . \mathrm{O}$ mesmo documento 
garante o direito a um recurso simples e rápido ou a qualquer outro recurso efetivo que a proteja contra atos que violem direitos $(\mathrm{CADH}$, art. 25). A Convenção visa dar efetividade às previsões na Declaração Universal (DUDH), encontrando-se sob Jurisdição da Corte Interamericana de Direitos Humanos (Corte IDH), em San José da Costa Rica. À Corte compete reafirmar as regras da Convenção perante os Estados que reconhecem sua Jurisdição, em caráter subsidiário, mesmo que tal subsidiariedade seja por ela interpretada restritivamente (RAMOS, 2013, p. 269).

No sistema regional africano, em conferência ministerial da Organização da Unidade Africana (OUA), hoje substituída pela União Africana (UA), foi aprovada em 1981, em Banjul, Gâmbia, a Carta Africana dos Direitos Humanos e dos Povos, que entrou em vigor em 21 de outubro de 1986. Na mesma linha dos demais documentos internacionais, a Carta reconhece a toda pessoa o "direito a que sua causa seja apreciada", acessando "os tribunais nacionais competentes contra qualquer ato que viole os direitos fundamentais que lhe são reconhecidos e garantidos pelas convenções, leis, regulamentos e costumes", nisso incluídos o direito de defesa, a presunção de inocência e o julgamento em prazo razoável (CADHP, art. $7^{\circ}$ ). A proteção deste e de outros direitos é realizada pela Corte Africana de Direitos Humanos e dos Povos (Corte ADHP), instalada em 2006 e sediada em Arusha, na Tanzânia, possuindo Juris dição sobre Estados-Nação que a tenham reconhecido (RAMOS, 2013, p. 238-239).

Em âmbito comunitário, relativo ao direito de integração entre os países membros da União Europeia, foi editada, no ano 2000, a Carta de Direitos Fundamentais da União. Consta em tal Carta que toda pessoa “cujos direitos e liberdades garantidos pelo direito da União tenham sido violados tem direito a uma acção perante um tribunal", para que sua causa seja "julgada de forma equitativa, publicamente e num prazo razoável, por um tribunal independente e imparcial, previamente estabelecido por lei”, devendo ser concedida "assistência judiciária a quem não disponha de recursos suficientes" (art. 47). Na mesma esfera, o Tratado sobre o Funcionamento da União Europeia, cuja reforma de 2007, realizada em Lisboa, surtiu efeitos em 2009, prevê que a entidade deverá facilitar o Acesso à Justiça, particularmente através do reconhecimento recíproco das decisões judiciais e extrajudiciais em matéria civil (art. 64), prevendo, ainda, a cooperação judicial para garantir a efetividade do direito (art. 81, parágrafo $2^{\circ}$ ).

O resguardo de tais normas e de outras que a complementam incumbe ao Tribunal de Justiça da União Europeia, sediado em Luxemburgo, e que não deve ser confundido com a Corte Europeia de Direitos Humanos (Corte EDH) (RUSSOWSKY, 2012, p. 01-21). 
Atualmente, contudo, firmou-se a posição no sentido de que os atos editados no processo de integração não devem violar os preceitos da Convenção Europeia de Direitos Humanos (CEDH) (RAMOS, 2013, p. 193-194), podendo ser sindicados quanto a tal fundamento, portanto, tanto no sistema regional europeu (Corte $\mathrm{EDH})$ quanto no próprio Tribunal de Justiça da União Europeia. Daí falar-se em uma "doppia dimensione europea" de proteção aos direitos humanos, que abrange a Europa entendida politicamente e aquela geograficamente considerada, contribuindo para uma aproximação não apenas econômica, mas também jurídica (OSTI, 2016, p. $118-119)^{11}$.

A partir da leitura dos instrumentos internacionais, constata-se que neles

(...) não há uniformidade quanto ao conteúdo dos enunciados normativos que positivam o direito de acesso à justiça. Em virtude da diversidade terminológica, nem sempre é possível determinar se a referência é feita ao direito de fazer uma reclamação perante um tribunal competente, ao direito de ter acesso a uma medida ou a um remédio jurídico capaz de impedir a consumação e uma ofensa, ou a prerrogativa do ofendido de impor ao violador o dever de reparar os prejuízos que lhe foram impingidos (MENDONÇA, 2016, p. 114).

Ainda assim, os documentos internacionais acima listados ${ }^{12}$ permitem algumas aproximações sobre como o Acesso à Justiça (lato sensu) é normatizado. Prioritariamente, o direito é previsto como a possibilidade de Acesso ao Poder Judiciário, concretizado por meio de "um processo equitativo, da garantia do contraditório, da publicidade, da imparcialidade e da independência, da proteção jurídica suficiente, da razoável duração do processo e do duplo grau de jurisdição" (MENDONÇA, 2016, p. 18). Secundariamente, na interpretação de expressões como 'recurso efetivo' para a solução de controvérsias, vem sendo incluído também o Acesso aos Direitos por meio de mecanismos extrajudiciais de resolução de conflitos, desde que céleres e idôneos (FRANCIONI, 2009, p. 03-06). Tem-se presente, então, uma noção ampla de Acesso à Justiça (lato lensu), entendido como a igualdade de aceder a esferas formais e informais (BOUEIRI, 2003, p. 223-252), isto é, "I tribunali e quan'altro risulti istituzionalmente predisposto allo scopo" de resolver conflitos, de um lado, e os "modi non istitizionali di gestione del conflitto" (BARBERIO, 2011, p. 06-07) ${ }^{13}$, de outro.

\footnotetext{
11 Tradução livre: "dupla dimensão europeia".

12 Optou-se por limitar a pesquisa, primordialmente, às sociedades ocidentes cuja cultura possui, em maior ou menor grau, a lguma afinida de. Mas, a título de curiosida de, o Acesso à Justiça ta mbém vem previsto em outros relevantes instrumentos naciona is como a Declaração Universal Islâmica de Direitos Humanos, de 1981 (art. IV), a Declaração do Cairo sobre Direitos Humanos no Islã, de 1990 (art. 19, b) e a Carta Árabe sobre Direitos Humanos de 1994 (art. $9^{\circ}$ ).

13 Tradução livre: "tribunais e quantos outros institucionalmente predispostos ao escopo" e "modos não institucionais de gestão de conflito".
} 


\subsection{Acesso individual à justiça internacional.}

As previsões normativas foram fortalecidas, ainda, com uma mudança de perspectiva.

À luz da teoria ortodoxa, o Direito Internacional Público seria um sistema de normas que rege as relações entre Estados, ao interno do qual estes são titulares de direitos e obrigações. Entre tais direitos estaria a possibilidade de submeter uma demanda a uma Corte Internacional, desde que com a anuência de Estados soberanos em submeter-se à Jurisdição externa. Ter-seia, enfim, uma percepção monista, centrada no Estado enquanto sujeito primário de direitos internacionais (FRANCIONI, 2009, p. 06-07). Tal percepção monista do Direito Internacional, aos poucos, evoluiu para outra, mais atenta ao indivíduo e aos interesses sociais, passando-se a admitir que cidadãos e pessoas privadas possam titularizar direitos no plano internacional (FRANCIONI, 2009, p. 07-09). E tal câmbio alterou, como segue, a teoria do Acesso à Justiça no Direito Internacional.

$\mathrm{Na}$ origem, um cidadão que sofresse dano no exterior poderia acionar a Justiça local para postular a reparação. Caso inexistissem ou fossem insuficientes os remédios jurídicos do país hóspede, ao indivíduo lesado caberia socorrer-se perante o país de origem, ao qual se abria a possibilidade de tornar sua a pretensão de seu cidadão, solicitando a proteção diplomática por denegação de justiça (LENZERINI; MORI, 2009, p. 150). O diniego di giustizia pode caracterizar-se, em suma, como um modo vasto de violação a direitos substanciais e processuais do estrangeiro, incluindo não só a negação de Acesso, mas o atraso injustificado, a deficiência na administração da justiça, um julgamento manifestamente injusto, um custo/caução demasiado para a propositura (FRANCIONI, 2009, p. 16) e etc. Em havendo a denegação, a reparação só poderia ser requerida pelo próprio Estado de origem, em substituição ao lesado, a quem os valores da indenização poderiam ou não ser discricionariamente repassados. Além disso, a pretensão não seria formulada perante um terceiro imparcial. A soma das circunstâncias enfraquecia, nas conformações iniciais do Direito Internacional, o Acesso de estrangeiros à Justiça (FRANCIONI, 2009, p. 11).

Paulatinamente, as decisões das Cortes de Direitos Humanos passaram a admitir a capacidade, inicialmente limitada e relativa a certas áreas do Direito, de o estrangeiro aviar diretamente remédios internacionais contra outros Estados, caso houvesse denegação de Acesso à Justiça. Na sequência, tal capacidade expandiu-se para que os indivíduos pudessem demandar, em similares circunstâncias, também seus próprios Estados de origem. Esse passo radical, verdadeira virada pro homine, acabou por deslocar o foco de análise, transferindo o problema 
do campo do direito do estrangeiro para a órbita dos direitos humanos internacionais (FRANCIONI, 2009, p. 29). Hoje o Acesso individual aos remédios internacionais conta com amplo reconhecimento, tanto na esfera dos direitos humanos como, ainda, no setor do direito internacional comunitário e econômico (FRANCIONI, 2009, p. 19-24), revelando-se um sistema subsidiário de Acesso à Justiça para a garantia de direitos. Assim é que, por exemplo, os Tribunais Europeu (Corte EDH) e interamericano (Corte IDH) admitem a propositura, perante eles, de ações individuais (RAMOS, 2013, p. 239-240), e o Tribunal Africano (Corte ADHP) permite tais ações desde que a possibilidade seja expressamente reconhecida pelos países que aderiram à sua Jurisdição (RAMOS, 2013, p. 272). Somente na Corte Internacional de Justiça (CIJ) é que ainda se apontam impedimentos estatutários à legitimidade ativa de indivíduos particulares (RAMOS, 2013, p. 94 e 104).

No âmbito do Direito Internacional, o Acesso individual à Justiça é classificado como um direito humano que "deve prima di tutto essere assicurato nell'ambito dell'ordinamento giuridico interno dello Stato in cui è avvenuta la lesione di um diritto e in particolare di um diritto umano" (FRANCIONI, 2009, p. 10) ${ }^{14}$, mas que, caso não o seja em níveis satisfatórios, autoriza os indivíduos a buscar a proteção subsidiária do Direito Internacional, especialmente perante as Cortes de Direitos Humanos. Chega-se a afirmar que o exercício desse right of individual petition "directly before international humans rights tribunals (such as the European, Inter-American and, more recently, African Courts)" fornece o testemunho de que "the jurisdictional solution constitutes the most perfected and evolved means of international protection of human rights" (CANÇADO TRINDADE, 2011, p. 49) ${ }^{15}$. O Acesso à Justiça internacional, assim, atua como um importante ingrediente de aprimoramento dos sistemas de proteção de direitos e de resolução de conflitos (MENDONÇA, 2016, p. 338).

Como já se registrou, "surely one of the greatest historical achievments of the international protection of human rights is the access of individuals to the international judicial organs of protection and the recognition of their procedural capacity in cases of violation of human rights" (CANÇADO TRINDADE, 2011, p. 32) ${ }^{16}$.

\footnotetext{
14 Tradução livre: “deve antes de tudo ser assegurado no ordenamento jurídico interno do Estado no qual se verifica a lesão a um direito e particularmente a um direito humano".

15 Tradução livre: "diretamente perante as Cortes Interna cionais de Direitos Humanos (como a Europeia, a Interamericana e, mais recentemente, as Africanas)" e "a solução jurisdicional constitui o mais perfeito e evoluído modo de proteção interna cionaldos Direitos Humanos".

16 Tradução livre: "Certamente, uma das maiores realizações históricas da proteção internacional dos direitos humanos é o acesso dos indivíduos a os órgãos judiciais internacionais e o reconhecimento de sua capacidade processualem casos de violação de direitos humanos".
} 


\subsection{Compreensão doutrinária e de Cortes internacionais.}

A Corte Europeia de Direitos Humanos conferiu, ao longo dos anos, uma intepretação evolutiva ao texto da Convenção (art. $6^{\circ}$ ). A literalidade do dispositivo, baseada na tradição do direito anglo-saxão e nos valores da justiça processual e da equidade, limita-se a enunciar os princípios e valores de um processo justo, deixando de afirmar o direito em si de, na fase da instauração, propor ou fazer uso do processo para proteger posições jurídicas substanciais. Mas a falta dessa expressa proteção foi superada pela Corte a partir da metade dos anos 70, quando houve a expansão do Estado social e dos direitos prestacionais (OSTI, 2016, p. 118-119). A Corte Europeia, assim, passou a conceber o Acesso à Justiça como um direito que "ocuppe une place si èminente" (Corte EDH, 1970, p. 11) ${ }^{17}$, cuja violação pode ser denunciada para sua intervenção.

De acordo com os parâmetros da case-law, a intervenção pressupõe uma disputa sobre um direito que se pode dizer, ao menos em bases arguíveis, reconhecido nas leis domésticas, mesmo que não o seja na Convenção Europeia dos Direitos do Homem. A disputa ainda "must be genuine and serious; it may relate not only to the actual existence of a right but also to its scope and the manner of its exercise" (Corte EDH, 2006, p. 45) ${ }^{18}$. Ademais, o resultado do procedimento deve ser diretamente decisivo para o gozo do direito, não sendo conexões tênues ou remotas suficientes para invocar a proteção da Convenção Europeia dos Direitos do Homem.

Referida Corte Europeia considera inseridos no Acesso à Justiça valores como a assistência jurídica pré-processual e processual, a equidade, a publicidade e a celeridade (OSTI, 2106, p. 120-121) ${ }^{19}$, devendo o Acesso, ainda, ser qualificado como prático e efetivo. O direito em estudo não se resume a um dever de não-ingerência estatal, englobando uma verdadeira e própria obrigação prestacional, de forma a garantir o aconselhamento técnico e a invocação da proteção do Estado, sem, contudo, excluir filtros baseados, por exemplo, na chance de sucesso da causa a ser proposta, isto é, se a causa é efetivamente sustentável em termos jurídicos para ser deduzida ou mesmo admitida em juízo (OSTI, 2016, p. 121-123). A Corte ainda valida as limitações nacionais que sejam compatíveis com a essência do direito, seja porque tenham um

\footnotetext{
17 Tradução livre: "ocupa um lugar tão eminente”.

18 Tradução livre: “deve ser genuína e séria; pode relacionar-se não apenas à existência de um direito, mas também ao seu escopo e à forma de seu exercício. O resultado dos procedimentos deve ser diretamente decisivo para o direito em questão".

19 A autora faz menção, no ponto, a conteúdo da decisão proferida no caso Golder vs United Kingdom: Corte EDH, 1975.
} 
escopo legítimo, seja porque guardem proporcionalidade entre os meios empregados e os fins perseguidos, tomando decisões caso-a-caso (OSTI, 2016, p. 125). Por fim, ela se reserva em um papel subsidiário e institui alguns filtros administrativos e jurisdicionais para sua atuação, fazendo-o com os objetivos manter com os Estados o dever primário de garantir o Acesso e, sobretudo, de racionalizar e gerir o elevado fluxo de processos que nela aporta, medida apta para "tutela proprio del buon funzionamento della Corte edu" (OSTI, 2016, p. 134) ${ }^{20}$.

A compreensão da Corte Europeia é resumida em importante precedente:

The right is not absolute, however. It may be subject to legitimate restrictions such as statutory limitation periods, security for costs orders, regulations concerning minors and persons of unsound mind (see Stubbings and Others $v$. the United Kingdom, judgment of 22 October 1996, Reports 1996-IV, pp. 1502-03, §§ 51-52; Tolstoy Miloslavsky v. the United Kingdom, judgment of 13 July 1995, Series A no. 316-B, pp. 80-81, §§ 62-67; and Golder, cited above, p. 19, § 39). Where the individual's access is limited either by operation of law or in fact, the Court will examine whether the limitation imposed impaired the essence of the right and, in particular, whether it pursued a legitimate aim and there was a reasonable relationship of proportionality between the means employed and the aim sought to be achieved (see Ashingdane v. the United Kingdom, judgment of 28 May 1985, Series A no. 93, pp. 24-25, § 57). If the restriction is compatible with these principles, no violation of Article 6 will arise (Corte EDH, 2001, p. 24) 21 .

O Tribunal de Justiça da União Europeia, na falta de um diploma próprio que abarcasse os direitos humanos, inicialmente reconheceu a aplicação analógica, no espaço comunitário, dos costumes gerais e da Convenção Europeia de Direitos Humanos. Isso ocorreu até que sobreveio a Carta dos Direitos Fundamentais da União Europeia, expressamente incorporando determinados direitos do homem, entre eles o Acesso à Justiça, que pode ser exercido em

\footnotetext{
20 Tradução livre: proteção adequada do bom funcionamento da Corte EDU”. Aqui, a autora registra a existência de documento conclusivo de Conferência realizada em Bruxelas, em 26-27 de março de 2015, que, na mesma trilha da Conferência de Brighton de 2012, firma o caráter subsidiário da Corte Europeia com a fina lida de de reduzir a carga de trabalho da Corte e de poder assegurar a razoá vel duração d as causas que lhe são submetidas.

21 Tradução livre: "O direito não é absoluto, no entanto. Pode estar sujeito a restrições legítimas, tais como prazos legais de prescrição, segurança para ordens de custos, regulamentos relativos a menores e incapazes (ver Stubbings e o. Contra o Reino Unido, acórdão de 22 de Outubro de 1996, Reports 1996-IV, pp. 150203, §§ 51-52; Tolstoy Miloslavsky contra o Reino Unido, acórdão de 13 de Julho de 1995, série A, n. 316 B, pp. 80-81, §§ 62-67, e Golder, já referido, 19, § 39). Onde o acesso do indivíduo é limita do por força de lei ou de fato, a Corte examinará se a limitação imposta prejudicou a essência do direito e, em particular, se buscou um objetivo legítimo e se havia uma relação de proporcionalidade razoável entre o m eios utiliza dos e o objectivo pretendido (ver Ashingdane c. Reino Unido, a córdão de 28 de Maio de 1985, Serie A n. 93, pp. 24-25, § 57). Se a restrição for compatível com esses princípios, não ocorrerá violação ao artigo 6"
} 
“duplice livello, comunitario e nazionale" (GESTRI, 2009, p. 465-466)22. Antes dessa incorporação, a comunidade apresentava normatizações eminentemente econômicas, nem sempre afinadas com a proteção de direitos fundamentais, o que veio a instar o Tribunal de Justiça, para manter padrões adequados e coerentes de funcionamento do sistema, a controlar, em conjunto com as Cortes nacionais, a adequação "dos atos normativos estatais", como também a aferir a compatibilidade dos "atos da própria UE com os direitos fundamentais catalogados na CEDH”'(MENDONÇA, 2016, p. 82)23.

Atualmente, na tarefa de compatibilizar a pluralidade dos textos normativos produzidos nos Estados, o Tribunal de Justiça da UE vem assentando, quanto ao Acesso à Justiça, que os padrões comunitários compreendem um recurso efetivo, judicial ou não, a ser assegurado sempre que houver confronto entre os regramentos dos Estados-membros e o direito da União Europeia, notadamente porque o direito à tutela jurisdicional faz parte dos princípios gerais comuns aos Estados e se acha garantido nas normas vigentes (OSTI, 2016, p. 127-129)24. O Tribunal de Justiça, porém, não o chancela como prerrogativa absoluta, admitindo que possa ser limitado por circunstâncias excepcionais, que encerrem razões públicas suficientes, desde que garantidos direitos invioláveis como a vida e a integridade física (MENDONÇA, 2016, p. $82)^{25}$. Além disso, o órgão tem instituído, como requisito para se acessá-lo, alguns pressupostos restritivos como individualidade, subsidiariedade e necessidade de prejuízos diretos (OSTI, 2016, p. 138), além de enfatizar a importância da mediação e da conciliação (PALANDRI, 2009, p. 501-532).

De acordo com a Corte Interamericana de Direitos Humanos, o Acesso à Justiça é "uno de los pilares basicos no sólo de la Convención Americana, sino del proprio Estado de Derecho en una sociedad democratica em el sentido de la Convención" (Corte IDH, 2006, p. 52) ${ }^{26}$. Tratase de um direito marcado por sua dimensão prestacional vertida no dever de disponibilizar recursos adequados para a tutela de direitos (MENDONÇA, 2016, p. 353). Também no sistema

\footnotetext{
22 Tradução livre: "nível dúplice: comunitário e nacional".

$23 \mathrm{O}$ autor faz menção a decisão proferida pelo Tribunal de Justiça no Acórdão Stauder, proferido no Processo n. 29/69, por meio do qual tal órgão "passou a visualizar os direitos humanos como parte integrante do conjunto de princípios gerais que orientam e oferecem sustentabilidade ao direito comunitário" (p. 82).

${ }^{24}$ A autora alude, aqui, à sentença proferida pelo Tribunal na causa C-222/84, sentença Johnston, de 15 de maio de 1986.

$25 \mathrm{O}$ autor ilustra a afirmação, no ponto, com julgado do Tribunal de Justiça no caso Lawless vs. Irlanda, 1961.

26 Tradução livre: “um dos pilares básicos não só da Convenção Americana, senão do próprio Estado de Direito em uma sociedade democrática no sentido da Convenção".
} 
do continente americano, aos Estados toca, marcadamente, o encargo primário de promover o Acesso à Justiça, observando uma interação entre os parâmetros estabelecidos pelo direito internacional e o dever interno, em certa medida discricionário quanto aos meios, de incrementar a acessibilidade.

A intervenção da Corte Internacional é subsidiária e reservada para após frustrados os recursos internos (OLIVEIRA; MAEOKA, 2009, 229-253), mesmo que a interpretação dada a esse caráter residual seja restritiva (RAMOS, 2013, p. 269). Dá-se ênfase ao dever de efetividade do processo, sob pena de violação às normas convencionais que vinculam os Estados-membros (MENDONÇA, 2016, p. 282) ${ }^{27}$. As decisões da Corte podem apresentar natureza jurídica declaratória e desconstitutiva, no sentido de invalidar atos internos dos Estados, como também condenatória, ao impor o dever de reparar os danos experimentos pela parte lesada (MENDONÇA, 2016, p. 80). A proteção judicial no sistema interamericano calca-se em pilares como a Jurisdição obrigatória da Corte, a executoriedade de suas decisões no plano doméstico e a "sagração do direito ao acesso à Jurisdição internacional enquanto direito fundamental" dos jurisdicionados (MENDONÇA, 2016, p. 274).

Dessa exposição resulta que as Cortes supranacionais e a doutrina comungam a percepção, já antes exposta, de que o Acesso individual à Justiça internacional se classifica como direito humano. E uma vez que os documentos internacionais adotam em seus textos, além do Acesso ao Poder Judiciário, terminologias diferentes como "remédio efetivo" ou "recurso efetivo", entende-se que tais previsões vêm assegurar mais do que a simples previsão de comparecimento perante um juízo competente, mas o direito de ter à disposição um meio idôneo a reparar o ato ilícito (FRANCIONI, 2009, p. 30), como a mediação, a conciliação e a arbitragem e outras esferas públicas ou privadas de resolução. Com tal compreensão, ficam abrangidos na ideia Internacional de Acesso à Justiça o Acesso ao Poder Judiciário e aos Direitos. Além disso, fica sensível a percepção de que, para a doutrina e as Cortes Internacionais, o mais importante é assegurar a efetividade dos direitos humanos substanciais, ainda que essa efetivação não ocorra pela via judiciária (MENDONÇA, 2016, p. 269). O caminho judicial é visto, em regra, como um instrumento para a proteção de outros direitos e não como um fim-em-si, sendo válidas as preocupações com o congestionamento excessivo dos recursos jurisdicionais, que vem em prejuízo à efetivação dos direitos.

Trata-se de um direito humano, só que de um direito humano de natureza, em regra, instrumental e vocacionada a permitir o gozo dos direitos substanciais primários (LENZERINI;

\footnotetext{
${ }^{27} \mathrm{O}$ autor registra, a respeito, a decisão proferida pela CIDH no caso Ximenes Lopes c. Brasil, de 2006. Rev. CEJUR/TJSC |Florianópolis (SC)| v.9. n.1|e364| p.01-19 |Janeiro-Dezembro | 2021.
} 
MORI, 2009, p. 155) previstos nas leis nacionais, nas Constituições ou em Tratados. O Acesso à Justiça (lato sensu) somente aparece como um direito autônomo quando o que se discute é a possibilidade ou a capacidade mesma de se aceder à tutela jurisdicional ou extrajudicial efetiva, ou, então, de se ter acesso à assistência jurídica para defesa criminal (FRANCIONI, 2009, p. 33-35).

Além disso, as Cortes Europeia e Interamericana convergem no sentido de que o Acesso ao Judiciário congloba o devido processo legal, o contraditório, a ampla defesa, a exigência de decisões motivadas e resultados justos e a razoável duração do processo (CANÇADO TRINDADE, 2011, p. 59-75), assim como os instrumentos necessários à defesa contra abuso de poder. Ou seja: "It is clear that the right of access to justice comprises not only the right to initiate proceedings before international human rights tribunals, but also the guarantees of due process of law" (CANÇADO TRINDADE, 2011, p. 71) 28 .

Baseada em tal acepção, a Corte Europeia já decidiu ser possível às instâncias superiores, em caso de manifesta ineficiência da atividade jurisdicional, avocar a causa e julgála independentemente do prévio pronunciamento dos níveis inferiores de Jurisdição (PACINI, 2008, p. 725-731). Além disso, admite-se a responsabilização dos Estados pela ineficiência judicial (MENDONÇA, 2016, p. 372).

Contudo, ainda que se verifique, na órbita internacional, um prestígio ao postulado da "azionabilità" dos direitos perante as Cortes Internacionais (LENZERINI; MORI, 2009, p. 151), ou "une tendance plutôt favorable à l'effectivité de ce droit" (DONIER et al, 2003, p. 49$50)^{29}$, não existem margens para absolutismos. Tem-se a construção de uma tipologia de limitações substanciais e processuais ao Acesso à Justiça, admitidas em respeito a outros direitos ou ao interesse público. Entre elas, a jurisprudência reconhece, por exemplo, a validade da fixação de prazos razoáveis de decadência ou prescrição, da renúncia voluntária ao direito de ação, da impossibilidade de se acionar certas pessoas sob determinadas circunstâncias, como no caso da imunidade diplomática sem abusos ou desvios, ou, ainda, do óbice a ações abusivas e vexatórias que colapsariam o sistema judicial (FRANCIONI, 2009, p. 39-42). Por outro lado, o Direito de Acesso é estendido também para a proteção das vítimas de atos criminosos, no sentido de que possam exigir o devido processamento do acusado (FRANCIONI, 2009, p. 18).

\footnotetext{
28 Tradução livre: "O direito de acesso à justiça compreende não somente o direito de iniciar processos perante Tribuna is Internaciona is de Direitos Hum anos, mas também as garantias do devido processo legal".

${ }^{29}$ Tradução livre: "uma tendência bastante favorável à efetividade desse direito". Rev. CEJUR/TJSC |Florianópolis (SC)| v.9. n.1|e364| p.01-19 |Janeiro-Dezembro | 2021.
} 
As Cortes Europeias e a Interamericana de Direitos Humanos carregam a árdua missão de avaliar se os sistemas jurídicos dos países sobre os quais exercem Jurisdição, dentro da liberdade de conformação de cada um e dos desafios organizacionais e de dosagem ligados ao tema, satisfazem ou não os padrões gerais de Acesso à Justiça constantes das Convenções. Se as Cortes entendem que as regras ignoram as exigências convencionais, elas põem-se a desenvolver uma concepção geral do instituto, que vem a condicionar os sistemas internos (DONIER et al, 2003, p. 48), numa análise, porém, equilibrada e atenta à necessidade de racionalização dos serviços judiciais para preservar sua própria eficácia. É assim, por um lado, que as Cortes não reconhecem um direito absoluto ao duplo grau de jurisdição e validam restrições razoáveis verificadas nos ordenamentos internos (DONIER et al, 2003, p. 48-49), porém, por outro lado, não admitem que o direito de Acesso "be at the mercy of limitations not provided for in the treaties, invoked by the States Parties for reasons or vicissitudes of domestic law" (CANÇADO TRINDADE, 2011, p. 49) ${ }^{30}$. Similar função também é exercida, em âmbito comunitário, pelo Tribunal Europeu.

De acordo com a doutrina atual sobre o tema:

Também no plano supraestatal, a concretização do acesso ao direito e à justiça é limitada em função da margem de discricionariedade permitida aos Estados, para elegerem os meios para o cumprimento das obrigações assumidas no plano internacional; e da sua qualificação como direito não absoluto, ainda que consagrado como prerrogativa fundamental que congregue os direitos à informação, à proteção jurídica e à tutela jurisdicional, individual e socialmente eficaz (MENDONÇA, 2016, p. 17$18)$.

Pode-se dizer que as Cortes Europeias e a Interamericana se equilibram entre limitar o voluntarismo dos Estados, para salvaguardar as Convenções, e preservar as considerações internas de ordem pública, nas matérias abertas à exclusiva conformação dos Estados (CANÇADO TRINDADE, 2011, p. 118). Ao decidir, as Cortes não têm o intento único de solucionar o caso concreto, senão também o de estabelecer padrões bussolares para situações futuras. Daí a afirmação de que as decisões "serve the wide purpose not only of resolving the legal questions raised in a given case, but also of clarifying and developing the meaning of the norms of the human rights treaty at issue" (CANÇADO TRINDADE, 2011, p. 193) contribuindo para a futura a observância pelos Estados-Partes. E para que as Cortes possam

\footnotetext{
30 Tradução livre: "fique à mercê de limitações não previstas nos Tratados, invocadas pelos Estados-partes por razões ou vicissitudes do direito interno".

31 Tradução livre: "servem ao amplo propósito não só de resolver as questões jurídicas surgidas em determinado caso, mas também de esclarecer e desenvolver o significado das normas dos Tratados de Direitos Humanos".
} 
cumprir tais tarefas, requer-se um alto grau de respeito à "the integrity and intangibility of the international jurisdiction"32 (CANÇADO TRINDADE, 2011, p. 113).

\section{CONCLUSÃO}

Com um sentido de considerações finais, importante ressaltar que o artigo procurou analisar o texto da Declaração Universal dos Direitos do Homem, da Convenção Europeia dos Direitos do Homem, da Convenção Americana Sobre Direitos Humanos, da Carta Africana dos Direitos Humanos e dos Povos, da Carta de Direitos Fundamentais da União Europeia e do Tratado Sobre o Funcionamento da União Europeia, bem como a maneira como o tema é encarado nas respectivas Cortes Internacionais, procurando-se integrar aspectos normativos, jurisprudenciais e doutrinários.

A partir do conteúdo estudado, propõe-se que o Acesso à Justiça (lato sensu), sob as lentes do Direito Internacional, seja conceituado ${ }^{33}$ como um direito humano no campo internacional e fundamental no campo doméstico, comumente positivado sob a forma de princípio, mas que também pode figurar de maneira implícita nos sistemas jurídicos. Possui um valor próprio, que se alia a uma função instrumental a outros direitos, dotando-se de um conteúdo complexo que permite enfoques técnico-processuais e democrático-institucionais. Compreende, preponderantemente, prestações estatais e condutas de atores privados, mas ainda incorpora aspectos de direitos de liberdade e participação. Especifica-se (stricto sensu) nas possibilidades de $(i)$ Acesso aos Tribunais para a proteção dos direitos pela via judiciária mediante um processo justo e revestido das garantias do due process of law, como o contraditório, a ampla defesa, a exigência de decisões motivadas, a publicidade, a imparcialidade, a razoável duração do processo e outras, e de (ii) Acesso aos Direitos em palanques extrajudiciais, em termos de informação, consultoria e métodos alternativos de resolução de conflitos, desde que eficientes. Todas essas noções interagem e têm seu conteúdo e extensão dependentes de atividades interpretativas, na tensão entre o grau de normatividade do direito e as restrições fáticas e jurídicas.

A pesquisa ainda levou a concluir, em termos gerais, que a negação pura e simples do Acesso à Justiça (lato sensu) é incompatível com o Direito Internacional tradicional, com os Direitos Humanos, com o Direito da União Europeia e com os Direitos Fundamentais. Contudo,

\footnotetext{
32 Tradução livre: "a integrida de e a intangibilida de da jurisdição internacional".

${ }^{33}$ Conceito elabora do com base em: SALLES, 2021, p. 36. 
apesar do prestígio de que desfruta o Acesso à Justiça e da tendência no sentido de protegê-lo, em nenhum dos sistemas internos e externos foi percebida, objetivamente, a positivação de um direito absoluto, admitindo-se toda uma tipologia de limitações substanciais e processuais decorrentes do respeito a outros direitos, do interesse público na organização dos serviços prestacionais, das articulações entre a esfera judicial e a extrajudicial e de condicionantes razoáveis que não violem a sua essência.

\section{REFERÊNCIAS BIBLIOGRÁFICAS.}

BARBERIO, Roberto. Il conflitto: radici e dinamiche storico-culturale. In: BARBERIO, Roberto; LUPO, Dario; GAUDENZI, Andrea Sirotti. Mediazione e conciliazione delle liti: rapporti con la giurisdizione e l'arbitrato. Aggiornato al decreto 'milleproroghe'" 2011. Forlì: Experta S.r..1, 2011.p.1-12.

BOUEIRI, Sonia. Una aproximación socio jurídica del acceso a la justicia. Revista CENIPEC. Mérida: n. 22, p. 223-252. Enero-diciembre 2003.

CÂMARA, Alexandre Freitas. O acesso à justiça no plano dos direitos humanos. In: QUEIROZ, Raphael Augusto Sofiati de (Org.). Acesso à justiça. Rio de Janeiro: Lumen Juris, 2002. p. 01-09.

CANÇADO TRINDADE, Antônio Augusto. The access of individuals to internacional justice. New York: Oxford University Press, 2011.

CICHOCKI NETO, José. Limitações ao acesso à justiça. $1^{a}$ ed (ano 1998), $6^{a}$ tir. Curitiba: Juruá, 2009.

COMISSÃO INTERAMERICANA DE DIREITOS HUMANOS. Convenção americana sobre direitos humanos. San José, 22 de novembro de 1969. Disponível em: < https://www.cidh.oas.org/basicos/portugues/c.convencao_americana.htm $>$. Acesso em 15 de novembro de 2015.

CONFORD, Tom. The meaning of access to justice. In: PALMER, Ellie; CONFORD, Tom; GUINCHARD, Audrey; e MARIQUE, Yseult. Access to justice: beyond the policies and politics of austerity. Oxford: Hart Publishing, 2016. p. 27-40.

CONSElHO DA EUROPA. Convenção europeia de direitos do homem. Roma, 04 de novembro de $1950 . \quad$ Disponível em: < http://www.echr.coe.int/documents/convention_por.pdf $>$. Acesso em 15 de novembro de 2017.

CORTE EUROPEIA DE DIREITOS HUMANOS. Baka vs. Hungary. n. 20261/12. 23 de junho de 2006. párr. 92. p. 45. Estrasburgo. Disponível em: 〈 http://www.echr.coe.int $>$. Acesso em 13 de novembro de 2017.

Case of $Z$ and Others vs. The United

Kingdom. n. 29392/95. párr. 93. p. 24. Estrasburgo. 10 de maio de 2001. Disponível em: < https://hudoc.echr.coe.int/ >. Acessado em 21 de fevereiro de 2019. 
. Delcourt vs. Belgium. n. 2689/65. 17 de janeiro de 1970. párr. 25, p. 11. Estrasburgo. Disponível em: 〈 http://www.echr.coe.int >. Acesso em 13 de novembro de 2017. Tradução livre: “ocupa um lugar tão eminente”.

21 de fevereiro de 1975. Estrasburgo. Disponível em: <
http://hudoc.echr.coe.int/app/conversion/pdf/?library=ECHR\&id=001 -

57496\&filename=001-57496.pdf $>$. Acesso em 19 de junho de 2018.

CORTE INTERAMERICANA DE DIREITOS HUMANOS. Caso López Álvares vs Honduras. 01 de fevereiro de 2006. párr 138, p. 52. San José. Disponível em: < http://www.corteidh.or.ct $>$. Acesso em 13 de novembro de 2013.

CRUZ, Alice Francisco da; SALLES, Bruno Makowiecky. Dos direitos humanos à sustentabilidade. In: ROSA, Alexandre Morais da; CRUZ, Alice Francisco da; QUINTERO, Jaqueline Moretti; e BONISSONI, Natammy. Para além do estado nacional: dialogando com o pensamento de Paulo Márcio Cruz. Florianópolis: Emais, 2018, p. 25-36.

DONIER, Virgine; LAPÉROU-SCHNEIDER, Béatrice; GERBAY, Nicolas; HOURQUEBIE, Fabrice; e ICARD, Philippe. Propos introductifs, In: DONIER, Virgine; LAPÉROU-SCHNEIDER, Béatrice (sous la direction). L'accès au juge: reserche sur l'effectivité d'un droit. Bruxelles: Bruylant, 2003. p. 21-50.

FRANCIONI, Francesco. Il diritto di acesso alla giustizia nel diritto internazionale generale. In: FRANCIONI, Francesco; In: FRANCIONI, Francesco; GESTRI, Marco; RONZITTI, Natalino; e SCOVAZZI, Tullio. Acesso alla giustizia dell'individuo nel diritto Internazionale e dell'unione europea. Milano: Giuffré, 2009.p. 03-44.

GESTRI, Marco. Portata e limiti del diritto individuale di accesso alla giustizia nell'ordinamento dell'unione europea. In: FRANCIONI, Francesco; GESTRI, Marco; RONZITTI, Natalino; SCOVAZZI, Tullio. Acesso alla giustizia dell'individuo nel diritto internazionale e dell'unione europea. Milano: Giuffré, 2009. p. 463-500.

LENZERINI, Federico; MORI, Rebecca. Accesso alla giustizia per i migranti a rischio di violazione dei diritti fondamentali. In: FRANCIONI, Francesco; GESTRI, Marco; RONZITTI, Natalino; e SCOVAZZI, Tullio. Acesso alla giustizia dell'individuo nel diritto Internazionale e dell'unione europea. Milano: Giuffré, 2009. p. 149-174.

MENDONÇA, J.J. Florentino dos Santos. Acesso equitativo ao direito e à justiça. São Paulo: Almedina, 2016.

OLIVEIRA, Cláudio Ladeira; MAEOKA, Erika. A Corte Interamericana de direitos humanos e a promoção do acesso à justiça. Scientia Juris: Londrina, v. 13, p. 229-253, novembro 2009.

ORGANIZAÇÃO DA UNIDADE AFRICANA (OUA). Carta africana dos direitos humanos e dos povos. Banjul, 21 de outubro de 1986. Disponível em: < http://www.achpr.org/pt/instruments/achpr/ >. Acesso em 15 de novembro de 2017. 
ORGANIZAÇÃO DAS NAÇÕES UNIDAS (ONU). Declaração Universal dos Direitos Humanos. Paris, 10 dezembro 1948. Disponível em: < http://www.onu.org.br/img/2014/09/DUDH.pdf >. Acesso em 15 de novembro de 2017.

OSTI, Alessandra. Teoria e prassi dell'access to justice: un raffronto tra ordinamento nazionale e ordinamenti esteri. Milano: Giuffrè Editore, 2016.

PACINI, Marco. Il diritto di accesso al giudici (Commento a corte europea dei diritti dell'uomo, sez. 5 ., 27 luglio 2007, ricorso n. 18806/02). Giornale di diritto amministrativo. v. 14, n. 7, p. 725-731. 2008. Disponível em: < http://www.irpa.eu/areabibliografica/scritti/il-diritto-di-accesso-al-giudice/ >. Acesso em 14 de novembro de 2017.

PALANDRI, Ivana. Mezzi alternativi di acesso alla giustizia nell diritto comunitario. In: FRANCIONI, Francesco; GESTRI, Marco; RONZITTI, Natalino; SCOVAZZI, Tullio. Acesso alla giustizia dell'individuo nel diritto internazionale e dell'unione europea. Milano: Giuffré, 2009. p. 501-532.

PASOLD, Cesar Luiz. Metodologia da pesquisa jurídica: teoria e prática. 13ed., rev., atual. e ampl. Florianópolis: Conceito Editorial, 2015.

PONTES DE MIRANDA, Francisco Cavalcanti. Comentários à constituição de 1967: com a Emenda n. 1 de 1969. $3^{\text {a }}$ ed. Tomo V. Rio de Janeiro: Forense, 1987.

RAMOS, André de Carvalho. Processo internacional de direitos humanos. 3d. São Paulo: Saraiva, 2013.

RICE, Thomas H. Speedy; REISMAN Brandie L. Access to justice for tort claims against a sovereign in the courts of the united states of America. In: FRANCIONI, Francesco; GESTRI, Marco; RONZITTI, Natalino; e SCOVAZZI, Tullio. Acesso alla aiustizia dell'individuo nel diritto Internazionale e dell'unione europea. Milano: Giuffré, 2009. p. 257-304.

RUSSOWSKY, Iris Saraiva. A relação do direito comunitário e o direito internacional regional. A adesão da união europeia ao sistema da convenção europeia de direitos Humanos. Cadernos de Pós-Graduação em Direito/UFRGS. v. VII, n. 01, p. 01-21, 2012.

SALLES, Bruno Makowiecky. Acesso à justiça e equilíbrio democrático: intercâmbios entre civil law e common law. v. 1. Belo Horizonte: Dialética, 2021.

UNIÃO EUROPEIA. Carta dos direitos fundamentais da união europeia (2000/C 364/01), 18 de dezembro de 2000. Disponível em: < http://www.europarl.europa.eu/charter/pdf/text_pt.pdf $>$. Acesso em 15 de novembro de 2017.

Tratado sobre o funcionamento da união europeia. Lisboa, 13 dezembro 2007. Jornal Oficial da União Europeia, C 306, 17 de Dezembro de 2007. Disponível em: < http://eur-lex.europa.eu/legal-content/PT/TXT/?uri=OJ:C:2007:306:TOC >. Acesso em 15 de novembro de 2017. 